\title{
Article \\ Complex Relationships: A Materials Study of Édouard Vuillard's Interior, Mother and Sister of the Artist
}

\author{
Abed Haddad *, Diana Hartman and Ana Martins \\ The David Booth Conservation Department, The Museum of Modern Art, 11W53rd Street, \\ New York, NY 10019, USA; diana@contemporaryconservation.com (D.H.); \\ a.martins@vangoghmuseum.nl (A.M.) \\ * Correspondence: abed_haddad@moma.org
}

Citation: Haddad, A.; Hartman, D.; Martins, A. Complex Relationships: A Materials Study of Édouard Vuillard's Interior, Mother and Sister of the Artist. Heritage 2021, 4, 2903-2917. https:// doi.org/10.3390/heritage4040162

Academic Editors: Valeria Di Tullio and Brenda Doherty

Received: 31 August 2021

Accepted: 28 September 2021

Published: 30 September 2021

Publisher's Note: MDPI stays neutral with regard to jurisdictional claims in published maps and institutional affiliations.

Copyright: (C) 2021 by the authors. Licensee MDPI, Basel, Switzerland. This article is an open access article distributed under the terms and conditions of the Creative Commons Attribution (CC BY) license (https:// creativecommons.org/licenses/by/ $4.0 /)$.

\begin{abstract}
Vuillard (1868-1949) is well known for his small atmospheric paintings, often portraying his own home and family as the subject matter. Interior, Mother and Sister of the Artist (1893) underwent at least one restoration treatment before being acquired by the Museum of Modern Art (MoMA) in 1934. The painting was treated again in 1954, but no analysis was carried out to understand the artist's methods and materials at that time. To better understand the choices of Vuillard in Interior, Mother and Sister of the Artist, a comprehensive suite of imaging and spectroscopic analyses was undertaken, including: XRR, UVF and IRR Photography, XRF, Raman spectroscopy and SERS, and $\mu$-FTIR. Statistical analysis on the XRF data using MCR-ALS further revealed some of the intricacies of Vuillard's technique and color choices, where a large number of pigments were used in designing this intimate composition, including lead white, zinc white, bone black, ochre, umber, vermilion, Geranium lake, red lead, ultramarine, Prussian blue, chrome yellow, chrome orange, zinc yellow, strontium yellow, cadmium yellow, and a chromium oxide green.
\end{abstract}

Keywords: Édouard Vuillard; X-ray radiography; ultraviolet fluorescence photography; infrared reflectography; X-ray fluorescence; Raman spectroscopy; Surface Enhanced Raman (SERS) spectroscopy; micro-Fourier Transform Infra-Red ( $\mu$-FTIR) spectroscopy; chemometrics

\section{Introduction}

\subsection{Art Historical Context}

Interior, Mother and Sister of the Artist (1893) is an iconic example of Édouard Vuillard's (1868-1949) small compositions, which often show glimpses within the artist's family home (Figure 1). Vuillard is well known for capturing moments of every-day life in his distinctly intimate interior paintings, which often focus on his mother and sister [1]. In the late 1890 's Vuillard joined a group of artists called Les Nabis [2]. This group of young French artists, which included his friend and studio mate Pierre Bonnard, believed that art should fundamentally be decorative [3]. Thematically, Vuillard explored this notion decorative with his use of patterning often seen in his depicted wallpaper and textiles, painted with dotted and patchwork brushstrokes. As part of the Nabis, he literally made his larger distemper paintings decorative by fitting them into the walls of apartments in addition to set designing for the Theatre de l'Oeuvre [3].

Mme Vuillard singularly raised Vuillard and his elder sister, Marie, by working as a seamstress following the death of her husband [1]. Boldly placed within the center of this composition, Vuillard's mother holds a steady gaze and strong posture suggesting her authoritative role as head of the household. Vuillard is known for adding theatrical tension within his compositions by closely cropping within a small interior and using a variety of patterns throughout his composition (Figure 1). In this painting, he uses this technique to add suspense in this portrayal of his sister. Her posture and outfit seemingly blend into the patterned wallpaper creating a moment of mystery and ambiguity to the narrative. 


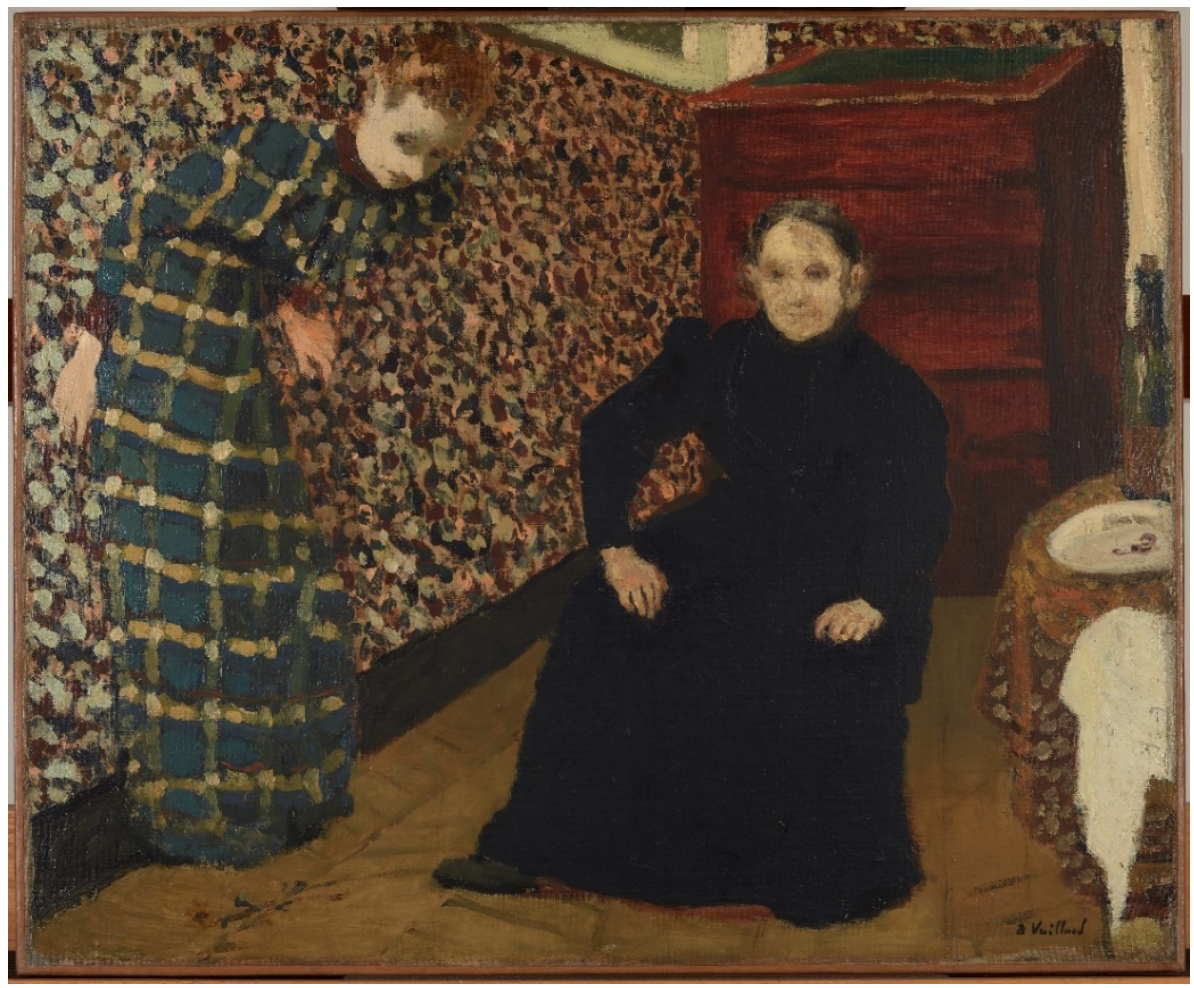

Figure 1. Édouard Vuillard Interior, Mother and Sister of the Artist. c. 1893 Oil on Canvas, $46.3 \times 56.5 \mathrm{~cm}$. The Museum of Modern Art. Gift of Mrs. Sadie A. May. 2021 Artists Rights Society (ARS), New York/ADAGP, Paris, all reproductions of this work are excluded from the CC: BY License.

\subsection{Treatment History and Current State}

The picture came into the collection in 1934 as a gift of Mrs. Saidie A. May to the Museum of Modern Art (MoMA). A 1954 conservation report describes the painting as oil paint applied onto a pre-primed canvas [4]. The primary canvas support is cut at the four outer-edges and glue-lined onto a secondary canvas support. Glue-paste linings were a common restoration practice in Europe up until the middle of the 20th century when other methods became more favorable [5]. Glue-paste adhesive recipes and lining methods have varied throughout time, country of practice, and within individual restoration studios but generally involve the use of a paste made from animal-based adhesive, flour and water and inert fillers [6]. This adhesive paste is used to adhere the original canvas to a secondary canvas using some amount of heat and pressure [5]. In some instances, such as in the case of Interior, Mother and Sister of the Artist, the edges of the painting itself were cut off before lining onto the secondary canvas. The cut edges are hidden by brown paper tape, but their absence is clearly denoted in the X-radiograph. The conservation report also mentions a yellowed varnish that was difficult to remove, and was almost certainly applied during the earlier restoration. Vuillard and the Nabis artists were influenced by impressionism and especially by the techniques of the post-impressionist painter Paul Gauguin, all of whom strongly preferred unvarnished surfaces [7]. The partial removal of this varnish was attempted but abandoned, which was followed by a spray coating of methacrylate varnish to even out the partially cleaned surface [4]. The lined painting is stretched over a wooden keyable stretcher with evenly spaced metal tacks on all four edges. The synthetic varnish applied in 1954 was then removed in 1979 and replaced by a brush coating of methacrylate varnish, followed by inpainting and final spray coating of another methacrylate varnish [8]. 


\subsection{Scientific Analysis}

Although the mysterious symbolism of this painting and the relationships between mother, sister, and Vuillard have been debated and analyzed in the past [9], the painting's method and materials have not yet been explored. Moreover, the technical literature on Vuillard's methods is scant, with only one work discussing his use of the distemper technique in larger "decorative" works [3] and another on his use of distemper on cardboard [10]. The results of this research are to the best of our knowledge the first to shed light on Vuillard's techniques for oil painting, a medium he used often for intimate portrayals of domestic life. To better understand the choices of Vuillard in Interior, Mother and Sister of the Artist, a comprehensive suite of imaging and spectroscopic analyses was undertaken, including X-ray Radiography (XRR), Ultraviolet Fluorescence (UVF) and Infrared Reflectography (IRR) photography, portable X-ray fluorescence (p-XRF) spectroscopy, Raman and Surface Enhanced Raman (SERS) spectroscopies, and micro-Fourier Transform Infra-Red ( $\mu$-FTIR) spectroscopy. Additionally, a multivariate approach was also explored to untangle some of the intricacies of Vuillard's preparatory layers and color choices and to shed more light on his technique. In the field of cultural heritage studies, Principal Component Analysis (PCA) is generally the method of choice because of its ease and has been used as an exploratory method to group samples based on similarity [11-17]. PCA reduces the dimensionality of a large dataset by extracting principal components (PCs) that maximize variance and retain descriptive information about the overall dataset [18]. However, PCA has its disadvantages, where PCs can become not as readily interpretable especially after pre-processing.

A more advanced multivariate technique, Multi Curve Resolution-Alternating Least Squares (MCR-ALS), can further harness the relationship between different chemical elements detected by $\mathrm{p}-\mathrm{XRF}$ for a more comprehensive analyses of the variance between acquired spectra $[19,20]$. Components extracted by MCR_ALS are readily interpretable as $\mathrm{XRF}$ spectra and present as an elemental signature from which pigments can be deduced. MCR-ALS was used successfully to extract and map pigments [21] or paints [22] using large area micro-XRF scanning; other approaches used for processing similar data include Non-negative Matrix Factorization (NMF) [23-25]. However, such instrumentation can be cost prohibitive and many more intuitions have portable units at hand. In this paper, we demonstrate that same MCR-ALS approach can be applied to a p-XRF data set to decompose the dataset into a collection of "pure components" and their relative abundance.

\section{Materials and Methods}

\subsection{Imaging}

XRR was performed with a $200 \mathrm{kV}$ Portable Industrial NDT X-ray Imaging System ( $35 \mathrm{kV}, 4.5 \mathrm{~mA}, 1.1 \mathrm{~m}$ distance and $270 \mathrm{~s}$ exposure). The radiographic image was recorded with a CareStream INDUSTREX XL Blue Digital Imaging Plate $(36 \mathrm{~cm} \times 43 \mathrm{~cm})$, which was scanned with a CareStream HPX-1 Computerized Radiography (CR) System. Images were visualized and processed using the Carestream Industrex Digital Viewing Software.

UVF Photography was carried out with a Canon EOS 5D Mark II (Zeiss Mak-ro-Planar $\mathrm{T}^{*}$ 2/50 ZE lens). The standard infrared filter was replaced by a 2E and a Peca \#918 UV blocking filters. UV illumination was provided by two Altman Spectra Cyc UV lamps, a $100 \mathrm{~W}$ cyclorama/wall wash luminaires with high output $365 \mathrm{~nm}$ UV LED emitters. The camera was calibrated with an X-rite ColorChecker Passport and a UV Innovation Target-UV ${ }^{\mathrm{TM}}$.

IRR imaging was carried out with a Canon EOS 5D Mark II with a removed IR filter modified for capture in the near infrared region (Hoya RM72 $67 \mathrm{~mm}$ filter). Illumination was provided by two Lowel Omni-Light ${ }^{\mathrm{TM}}$ (500 W, 120 V Bulb, 120-240 VAC/12-30 VDC).

Surface microscopy was carried using low power magnification with a Wild Heerbrugg binocular microscope with a $6 \times-200 \times$ range and illumination by a fiber-optic light source, Intralux 6000, at $3200 \mathrm{~K}$ color temperature. Images were captured using an Apple iPhone XR @ through a single eyepiece. All microscopic images of the surface were white balanced in Adobe Photoshop 2021. 


\subsection{Synthesis of Silver Nanoparticles for SERS}

Silver nanoparticles (AgNPs) were prepared according to a method developed by Lux et al. [26]. A solution of $12.5 \mathrm{~mL}$ of $0.5 \mathrm{mM} \mathrm{Ag}_{2} \mathrm{SO}_{4}(\geq 99.99 \%), 0.5 \mathrm{~mL}$ of $1 \%$ sodium citrate dihydrate $(\geq 99 \%)$, and $1 \mathrm{~mL}$ of $1 \%$ D-glucose $(\geq 99.5 \%)$ are mixed in a Hydrothermal Synthesis Autoclave Reactor PTFE Tank (Baoshishan, China) previously cleaned with nitric acid at $30 \%$. Once closed, the vessel was positioned in the center of a Panasonic model NN-SD372S inverter microwave and heated at $810 \mathrm{~W}$ for $2 \mathrm{~min}$. Then, $1.5 \mathrm{~mL}$ aliquots of this stock solution of citrate-capped AgNPs were centrifuged at 12,000 rpm for $15 \mathrm{~min}$. The supernatant containing the citrate solution in excess was removed and replaced by distilled water to avoid sodium citrate interference in the SERS spectra. The sample was pretreated with $\mathrm{HNO}_{3}$ to hydrolyze any lakes present into the colloidal solutions by breaking the bonds with the base onto which the dye was precipitated. All chemicals were purchased from Millipore-Sigma, USA.

\subsection{Instrumental Analysis}

p-XRF spectroscopy analysis was performed with a Bruker Tracer III-SDD handheld $\mathrm{XRF}$ instrument with a Rh excitation source, a silicon drift detector and with a $5 \mathrm{~mm}$ diameter approximate spot size. The instrument was operated at $40 \mathrm{kV}$ and $3 \mu \mathrm{A}$, and spectra were acquired for $120 \mathrm{~s}$ under He purge. A total of 41 spectra were acquired over the whole painting to capture enough data for the statistical analysis and three from the verso to help characterize the ground layer. All the spectra were evaluated with the Bruker Artax 8.0 software.

$\mu$-FTIR spectroscopy analysis was carried out using a Nicolet iS50- $\mu$-FTIR coupled with a Thermo Nicolet Continuum infrared microscope equipped with an MCT detector. Samples were prepared on a diamond cell to analyze in transmission mode. Spectra were collected in the $4000-600 \mathrm{~cm}^{-1}$ range with a $4 \mathrm{~cm}^{-1}$ resolution and 128 scans using the Thermo Scientific OMNIC 9.0 software package. Spectra were examined using the Spectral Search and Multicomponent Search tools available in the Thermo Scientific OMNIC Specta 2.0 software and IRUG spectral databases [27].

Raman spectroscopy was carried out using a Renishaw In-via Raman system equipped with a $785 \mathrm{~nm}$ diode laser operated between 0.3 to $3 \mathrm{~mW}$, a 1200 lines $/ \mathrm{mm}$ grating, and a Leica confocal microscope with a $50 \times$ LWD or $100 \times$ objective. Final spectra represent an average of five acquisitions of $10 \mathrm{~s}$. Surface Enhanced Raman (SERS) spectroscopy was carried out using the same system but equipped with a $532 \mathrm{~nm}$ diode laser operated at 0.25 $\mathrm{mW}$, an evaluated using Spectral Search and Multicomponent Search tools available in the Thermo Scientific OMNIC Specta 2.0 software and a spectral database from UCL [28].

Samples for micro-invasive analysis were taken from the edges of the painting under low magnification using a Wild Heerbrugg binocular microscope (see Section 2.1 Imaging) with a scalpel, after which they were deposited onto a well microscope slide.

\subsection{Statistical Analysis}

The statistical treatment of the p-XRF data was carried out using SOLO + MIA 8.9.1 from Eigenvector Research Inc. The XRF spectra were arranged in a 2D dataset and truncated to a range of 1 and $16.5 \mathrm{keV}$ to avoid interference from sum peaks of high-count elements and other artefacts. Exploratory investigation of the data was carried out using principal component analysis (PCA) for an initial assessment of the relationships between the spectra and thus between the paint spots examined. The data were pre-processed to better exploit variance for separation and clustering. Poisson scaling [29] was used to enhance the signal intensity of less prevalent and lower $Z$ elements to which the instrument is less sensitive; the data were also mean centered.

Further analysis with Multi Curve Resolution-Alternating Least Squares (MCR-ALS) with contrast enhancement $[20,22]$ was used to decompose the XRF spectra into individual components/contributions from pigments and paints. MCR-ALS is a bilinear factor de- 
composition method solved by alternating least squares optimization [19]. The model can be described in linear algebra terms by:

$$
\mathrm{D}=\mathrm{CS}^{\mathrm{T}}+\mathrm{E},
$$

where $\mathrm{D}$ is the experimental matrix that contains the acquired $\mathrm{p}-\mathrm{XRF}$ spectra; $\mathrm{S}^{\mathrm{T}}$ (spectra) and $C$ (concentrations or abundance) are the factor matrices obtained by bilinear decomposition that correspond to the spectral signatures and magnitude profiles, respectively, of the pure components extracted; and E refers to the non-modelled residual contributions matrix and can be interpreted as instrumental noise. The method imposes non-negative constraints but maximum orthogonality between component profiles can be achieved by applying contrast enhancement of either spectra or contributions [20]. In this study, contrast enhancement was imposed on contributions instead of spectra to extract the spectral profiles of pigments or paints as opposed to the spectral profiles of the chemical elements which is a priori knowledge in the case of p-XRF. The components loadings were interpreted as spectral fingerprints for the pigments and paints while the scores were used as a direct measure of their abundance in each paint spot. The data were only Poisson scaled for MCR-ALS.

\section{Results and Discussion}

\subsection{The Palette}

Analysis of the painting (summarized in Table 1) was mostly undertaken non-invasively using p-XRF, where the following elements were identified: $\mathrm{Al}, \mathrm{Si}, \mathrm{P}, \mathrm{S}, \mathrm{K}, \mathrm{Ca}, \mathrm{Ti}, \mathrm{Cr}, \mathrm{Mn}$, $\mathrm{Fe}, \mathrm{Co}, \mathrm{Zn}, \mathrm{Br}, \mathrm{Sr}, \mathrm{Cd}, \mathrm{Ba}, \mathrm{Hg}$ and $\mathrm{Pb}$. The use of $\mathrm{p}$-XRF relies on a priori knowledge of pigment composition and is not a fingerprint technique. In as much, the following pigments and fillers were first inferred from the elemental analysis of the spectra, in combination with the color of the location from which they were acquired: lead white $\left(2 \mathrm{PbCO}_{3} \cdot \mathrm{Pb}(\mathrm{OH})_{2}\right)$, zinc white $(\mathrm{ZnO})$, bone black (hydroxyapatite $\left(\mathrm{Ca}_{5}\left(\mathrm{PO}_{4}\right)_{3}\right)$, ochre $(\mathrm{Fe}$, $\mathrm{Al}, \mathrm{Si}, \mathrm{K}, \mathrm{Ti})$, umber $(\mathrm{Fe}, \mathrm{Mn}, \mathrm{Al}, \mathrm{Si}, \mathrm{K})$, vermilion $(\mathrm{HgS})$, eosin lake $\left(\mathrm{C}_{20} \mathrm{H}_{6} \mathrm{Br}_{4} \mathrm{Na}_{2} \mathrm{O}_{5}\right)$, Prussian blue $\left(\mathrm{Fe}^{\mathrm{III}}\left[\mathrm{Fe}^{\mathrm{II}}(\mathrm{CN})_{6}\right]_{3}{ }^{-}\right)$, Cobalt Blue $\left(\mathrm{CoO} \cdot \mathrm{Al}_{2} \mathrm{O}_{3}\right)$ chromium-based pigments, either lead chromate yellow/orange $\left(\mathrm{PbCrO}_{4} / \mathrm{PbO}-\mathrm{CrO}_{3}\right)$ or viridian/chromium oxide green $\left(\mathrm{Cr}_{2} \mathrm{O}_{3} \cdot 2 \mathrm{H}_{2} \mathrm{O} / \mathrm{Cr}_{2} \mathrm{O}_{3}\right)$, strontium yellow $\left(\mathrm{SrCrO}_{4}\right)$ cadmium yellow (CdS), barite and/or lithopone $\left(\mathrm{BaSO}_{4} / \mathrm{ZnS}\right)$, calcium based fillers $(\mathrm{Ca})$, and clay-based fillers $(\mathrm{Al}, \mathrm{Si})$. Some of these pigments are in line with documented preferences of Vuillard, albeit that research dealt with his work using distemper rather than oil media [3]. In any case, those pigments include: zinc white, cadmium yellow, Prussian blue, red earths, red lakes, and vermilion.

Initial investigation of the $\mathrm{p}-\mathrm{XRF}$ dataset with PCA showed that a spectrum taken from the daughter's sleeve to contain a large amount of $\mathrm{Br}$ and $\mathrm{Pb}$ relating to the presence of eosin and lead white in a thick brushstroke which skewed the resulting score plot. Consequently, this outlier was excluded from the MCR-ALS analysis. This method was used to extract and characterize the spectral contribution of the different pigments present in the paints used by Vuillard and better elucidate his technique. The components extracted identified several key pigments used in the picture, including lead white, zinc white, umber, ochre, a lead chromate, zinc yellow, vermilion, Prussian blue, and a chromium-based oxide green (Figure 2). Vermilion was only extracted alongside zinc yellow, but that could be only a function of the spots chosen and not speak directly to the presence of vermilion elsewhere in the picture. The results of the MCR-ALS analysis will be discussed along with the artist methods and interpretation of the imaging and spectroscopic results to best show the working methods of Vuillard. 
Table 1. The Pigments Identified in Interior, Mother and Sister of the Artist by Technique.

\begin{tabular}{|c|c|c|c|c|c|}
\hline Pigment & UVF & IRR & $\mathrm{p}$-XRF & Raman & $\mu$-FTIR \\
\hline Zinc White & $x$ & & $x$ & & \\
\hline Lead White & & & $x$ & $x$ & $x$ \\
\hline Bone Black & & $x$ & $x$ & & \\
\hline Umber & & & $x$ & & \\
\hline Ochre & & & $x$ & & $x$ \\
\hline Chrome Yellow & $x$ & & $x^{*}$ & $x$ & \\
\hline Strontium Yellow & & & $x$ & & \\
\hline Cadmium Yellow & $x$ & & $x$ & & \\
\hline Zinc Yellow & & & $x^{*}$ & $x$ & \\
\hline Chrome Orange & & & $x^{*}$ & $x$ & \\
\hline Vermilion & & & $x$ & $x$ & \\
\hline Red Lead & & & & $x$ & \\
\hline Eosin & $x$ & & & $x^{* *}$ & \\
\hline Chromium Oxide Green & & & $x$ & & \\
\hline Prussian Blue & & $x$ & $x^{*}$ & & \\
\hline Ultramarine & & & $x$ & $x$ & \\
\hline Cobalt Blue & & & $x$ & & \\
\hline
\end{tabular}

* These results were inferred from the color of the location on the picture from where the spectrum was acquired *** Identification of eosin Y required SERS.
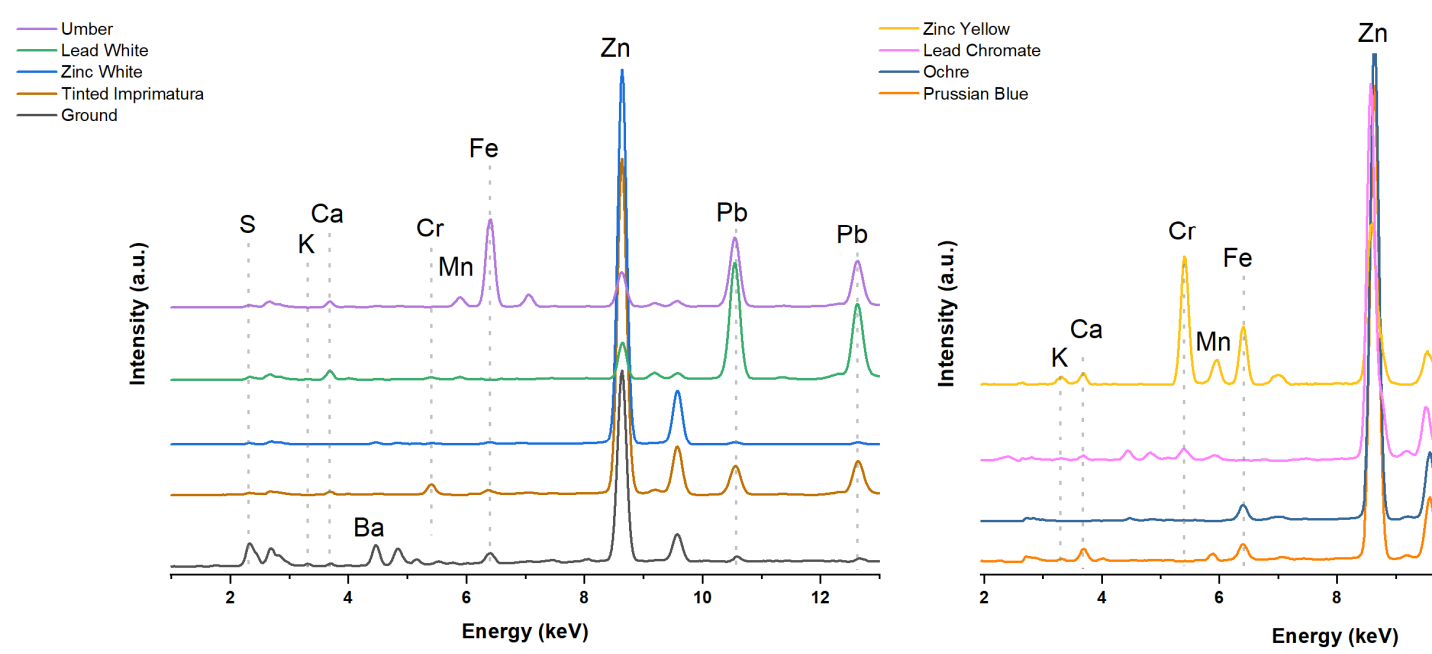

Figure 2. MCR-ALS loadings extracted from the XRF dataset and representing some of the pigments/paints used in Interior, Mother and Sister of the Artist. *. Vermilion was always associated with zinc yellow in the spots analyzed by XRF.

Further analysis to confirm some of these pigments was carried out by $\mu$-FTIR and Raman spectroscopies. The former is more sensitive to iron oxides, clay fillers, and possible binding media present, whereas the latter is more sensitive to semiconductor pigments. $\mu$-FTIR and Raman spectroscopies required sampling, which was confined to the edges of the composition where possible and as such these results are not comprehensive but complementary to $\mathrm{p}-\mathrm{XRF}$. It is worth noting that the presence of an oil medium was detected in all $\mu$-FTIR spectra through the presence of the characteristic bands at 2956 (sh), 2956, 2854, 1738 and $1713 \mathrm{~cm}^{-1}$ [30]. In some Raman spectra, the oil medium in addition to the natural resin varnish generated enough fluorescence that hindered interpretation.

In his re-working and abrading of the surface paint layers, Vuillard allowed some areas of prepared canvas and intermediate working layers (Figure 1) to remain visible. A sample was taken from area of scraped paint near the plate on the right edge of the composition. The presence of lead white in that exposed area was confirmed by both Raman (1050 and $413 \mathrm{~cm}^{-1}$ ) [28] and $\mu$-FTIR (Figure 3) $\left(3537,1411,1045\right.$, and $681 \mathrm{~cm}^{-1}$ ) [30]. A yellow particle in the sample was identified by $\mu$-FTIR (Figure 3 ) as an iron oxide, possibly ochre, mainly by the presence of strong signal for silicates (3620, 3698, 1164, 1091, 1032, 1010, 
and $912 \mathrm{~cm}^{-1}$ ) [31]. That particle also showed a strong presence of hydrated carbonates, including calcium carbonate $\left(3393,1416\right.$, and $\left.875 \mathrm{~cm}^{-1}\right)$ [30] and another, unidentified peak at $1570 \mathrm{~cm}^{-1}$, possibly of zinc and/or lead carboxylates [32,33]. On the other hand, the $\mathrm{p}$-XRF spectra taken from that area shows strong lines for $\mathrm{Zn}$ and $\mathrm{Pb}$, in addition to minor peaks of $\mathrm{Ca}, \mathrm{Ba}, \mathrm{Cr}$. The $\mathrm{p}-\mathrm{XRF}$ spectra taken from another area of exposed ground found near the top peripheral edge of the composition showed intense $\mathrm{Zn}$ and $\mathrm{Pb}$ lines with additional peaks for $\mathrm{Ba}$ and $\mathrm{S}$ and $\mathrm{Ca}$. $\mathrm{p}-\mathrm{XRF}$ analysis was also performed on the verso of the canvas, where attenuation of the $\mathrm{Pb}$ and $\mathrm{Ba} \mathrm{La}_{1}$ lines [34] suggests that there are two preparatory layers, possibly one containing $\mathrm{Pb}$ and/or $\mathrm{Zn}$ and another layer containing $\mathrm{Pb}$ and $\mathrm{Ba}$. However, interpretation of those spectra for ground identification could be misleading due to the lining treatment, which might contain inert fillers, as suggested by the intense peaks for Ca and S [6], and could further contribute to the attenuation. The MCR-ALS analysis brings further clarification on the canvas stratigraphy by extracting two components belonging to subsurface layers. One of the components extracted, the ground (Figure 2, that is common to the all the spots and dominant for the spot taken from the edge with the exposed ground shows intense peaks for $\mathrm{Zn}, \mathrm{Ba}$, and $\mathrm{S}$, and some Fe and $\mathrm{Pb}$. This confirms that the primary ground contains lithopone $\left(\mathrm{BaSO}_{4} / \mathrm{ZnS}\right)$ and /or zinc white and barite also identified in the spectra from the verso; the presence of $\mathrm{Fe}$ is either related to impurities or an oxide pigment for tint. The presence of small amounts of $\mathrm{Pb}$ in the primary ground is not unusual, as lead white was used as an adulterant in zinc white formulations during that time [35]. The inherent darkening of lithopone in addition to the discolored coating of yellowed varnish might explain why the exposed areas of the ground now appear dark brown; lithopone can become unstable with age and can darken over time [5]. It appears the ground was further covered by the artist with an application of a thin imprimatura layer composed of zinc white paint that contains lead white, chrome yellow/orange, an iron oxide, and a calcium filler, possibly calcite $\left(\mathrm{CaCO}_{3}\right)$. This information was extracted by MCR-ALS (Figure 2) and confirms the $\mu-$ FTIR analysis of the sample taken from the exposed area near the plate, albeit chrome yellow/orange was only inferred from the p-XRF analysis in combination with MCR-ALS. This could point to Vuillard employing an imprimatura to impart warm undertones onto the overall composition [3]. Another component extracted by MCR-ALS was for Prussian blue, an iron-based anionic organometallic $\left(\mathrm{Fe}^{\mathrm{III}}\left[\mathrm{Fe}^{\mathrm{II}}(\mathrm{CN})_{6}\right]_{3}^{-}\right)$pigment. Prussian blue is charge balanced using $\mathrm{NH}_{4}{ }^{+}, \mathrm{K}^{+}$, or additional iron during synthesis. This component extracted shows peaks for both Fe and K, in addition to zinc white, lead white and a calcium filler. Prussian blue varieties balanced with potassium is in line with 19th century paint formulations [36]. Prussian blue was most prominently used in the dark blues of the sister's dress.

Raman analysis brought additional clarity to the p-XRF results (Figure 4). A salmoncolored sample from near the right edge was found to be a combination of vermilion (252 and $\left.342 \mathrm{~cm}^{-1}\right)$, chrome orange $\left(147,378,852\right.$, and $\left.845 \mathrm{~cm}^{-1}\right)$, and a barite filler $\left(988 \mathrm{~cm}^{-1}\right)$ [28]. Chrome orange, or $\mathrm{PbO} \cdot \mathrm{CrO}_{4}$, is mainly produced by treating a neutral lead chromate with alkalis or precipitation of alkaline solutions, and its hue is mainly determined by the particle size, ranging from red to orange [37]. This combination of vermilion and chrome orange was also used in a mixture with an iron oxide (p-XRF) in the dark ochre used for the interior's floor. Two more chromate pigments, chrome yellow or $\mathrm{PbCrO}_{4}\left(360,380\right.$ and $\left.842 \mathrm{~cm}^{-1}\right)$ in conjunction with zinc yellow $(342,871$, and $936 \mathrm{~cm}^{-1}$ ) [28] were identified in the dark brown molding depicted at the top edge of the picture. Zinc yellow $\left(\mathrm{ZnCrO}_{4}\right)$, is a complex zinc potassium chromate with the approximate composition $\mathrm{K}_{20} \cdot 4 \mathrm{ZnCrO} \cdot 3 \mathrm{H}_{2} \mathrm{O}$, and a few varieties can be made with different ratios of $\mathrm{ZnO}$ and $\mathrm{Cr}_{2} \mathrm{O}_{3}$ as starting materials [37]. MCR-ALS grouped vermilion with the use of zinc yellow, as the former was only detected in the mother's hands along with the latter, however Raman analysis confirms the presence of vermilion elsewhere in the picture. This discrepancy between techniques was a function of the spots chosen for p-XRF analysis. Finally, a blue sample from the left edge was analyzed and contained ultramarine blue 
(437 and $546 \mathrm{~cm}^{-1}$ ) [28] in addition to a barite filler. Raman analysis here was crucial to confirm the presence of ultramarine blue, which is mainly composed of lighter elements $\left(\mathrm{Na}_{8-10} \mathrm{Al}_{6} \mathrm{Si}_{6} \mathrm{O}_{24} \mathrm{~S}_{2-4}\right)$ that can be below the detection limit of $\mathrm{p}-\mathrm{XRF}$, and highlights the value of complementary technical analysis.

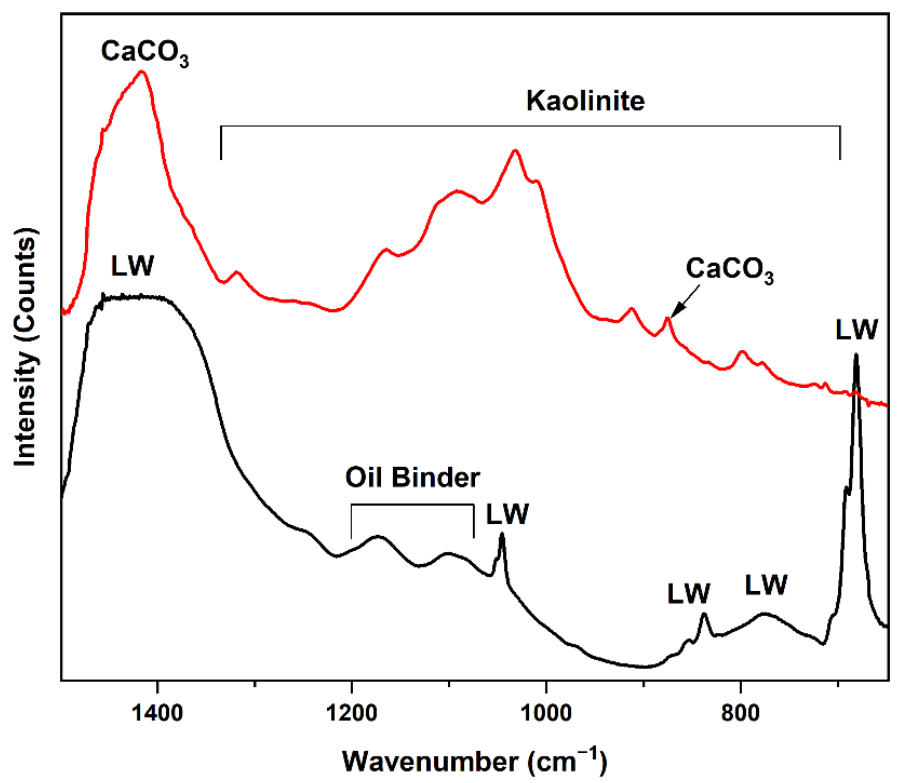

Figure 3. $\mu$-FTIR of two different particles in a sample taken from the tinted imprimatura, where the one shows (red) the presence of kaolinite and calcium carbonate $\left(\mathrm{CaCO}_{3}\right)$ and the other the presence of lead white (LW) and an oil binder.

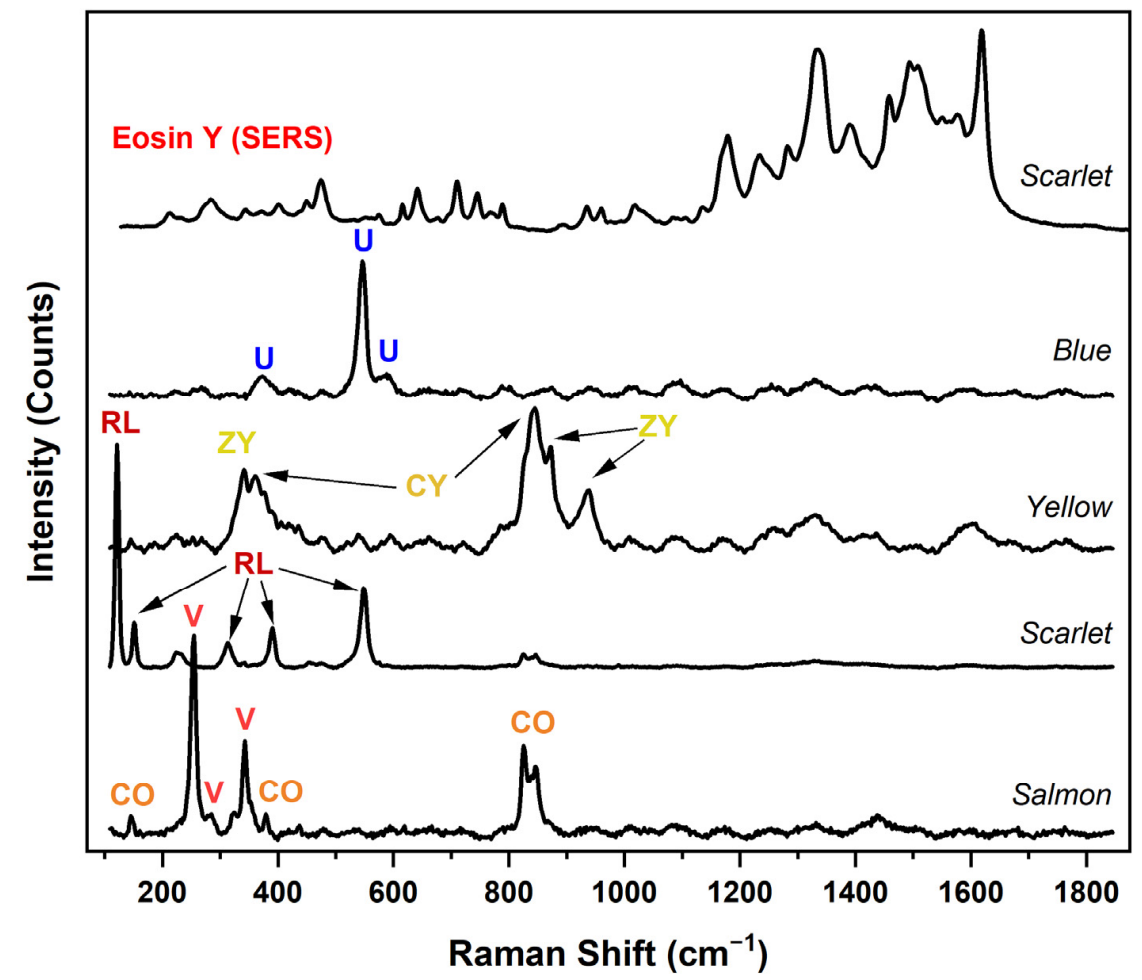

Figure 4. Raman spectra of pigments identified in samples taken from Interior, Mother and Sister of the Artist. CO: Chrome Orange. V: Vermilion. RL: Red Lead. ZY: Zinc Yellow. CY: Chrome Yellow. U: Ultramarine blue. The top spectrum was acquired by SERS and shows the presence of eosin $Y$, an organic lake pigment. 
A sample that was investigated with SERS (Figure 4) was a scarlet-colored one taken from the left edge. Analysis with normal Raman showed the presence of strong bands for red lead (121, 150, 233, 290, 313, 477, and 548) [28], a pigment $\left(\mathrm{Pb}_{3} \mathrm{O}_{4}\right)$ that would have been difficult to characterize with $\mathrm{p}-\mathrm{XRF}$ alone considering the prevalence of the lead white. Approaching the sample with prior knowledge of the presence of $\mathrm{Br}$ from $\mathrm{p}-\mathrm{XRF}$ analysis, SERS was employed to confirm the presence of Geranium lake, namely eosin Y $(213,283,344,372,401,450,475,575,615,641,679,710,768,789,960,1018,1179,1234$, $1282,1334,1390,1458,1508,1550,1576$, and $1619 \mathrm{~cm}^{-1}$ [38]; peaks at 935 and $1493 \mathrm{~cm}^{-1}$ are peaks ascribed to the citrate capping agents of the AgNPs). Identification of this lake pigment is paramount to understanding Vuillard's color choices, but also for conservation implications considering that eosin is of the most fugitive lakes, and passages that contain the pigment could have looked more vivid when the picture was first executed [39-41].

\subsection{Interpretation of Imaging}

Technical imaging of the painting was carried out with a range of techniques that allowed a clearer interpretation of the artist's working method as well as the painting's condition and past conservation treatments (Figure 5). The technical imaging also informed further elemental and chemical analysis. Surface examination using visible light revealed a glossy surface from the layers of applied restoration varnishes. The "stubborn varnish" mentioned in the 1954 conservation report has yellowed with age and is clearly visible in UVF (Figure 5), appearing as a thick and oxidized milky green color characteristic of a natural resin varnish [42]. The partial removal of the natural resin varnish [4] can be seen throughout the surface and is evident from the tops of the canvas nub texture in some areas, but other areas are left intact, such as the mother's dress. The varnish was removed to a greater extent in areas of white pigment such as the tablecloth and plate, the hands, and faces. It is common to see discolored varnish selectively reduced in areas of less solvent-sensitive paint colors, usually in passages containing white paint. Small areas of restoration retouching are seen in UVF that appear as non-fluorescent marks.

XRR penetrated the brown edge tape, presumably applied during the early restoration, and revealed the canvas was cut along all four edges. Roughly 4 to $7 \mathrm{~mm}$ of ground was left unpainted along the outer boundaries of the composition. Whether this is the result of the reformatting of the painting during the restoration or the choice of the artist is not clear but if the former, this would point to a commercially applied ground as they usually extend to the edges. The weave under the composition shows more contrast than the exposed canvas around the edges. Those edges are also less radio opaque than the areas of exposed canvas for example around the plate. This suggest the presence of an imprimatura layer that is also visible in normal light as a brighter warm brown that extends slightly over the darker brown lithopone ground along the edge. The presence of two preparation layers is in agreement with the results obtained by XRF analysis. The paint and ground layers in the mother's face have been so heavily abraded that the area shows very low radiopacity (Figure 5). The paint and ground have been retained in the face's outer perimeter and a comparison of the XRR with the visible light images suggests there were minor changes to the size and shape of the face and ear placement. In addition, there is some faint radiopaque modeling seen in the mother's dress which is not seen in visible light and can be interpreted as a compositional change, possibly done in lead white as indicated by p-XRF. In contrast to the mother's face, the sister's face is painted with a thick application of opaque paint, with no exposed ground and no evidence in the XRR of scraping or sanding underneath (Figure 5). The XRR image does suggest some minor changes were made in the shape of the nose and mouth, but these changes are more subtle than in the rendering of the mother. 

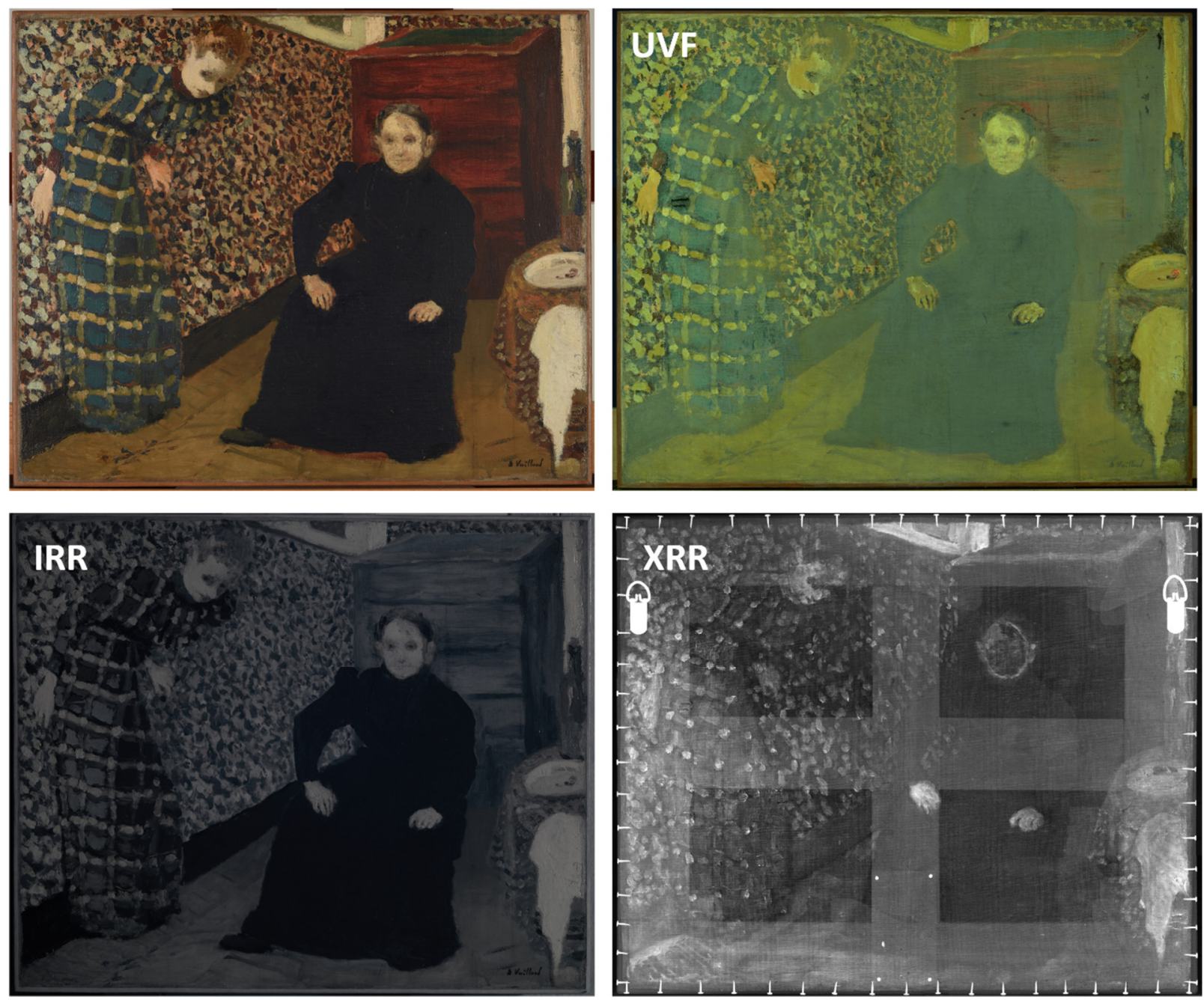

Figure 5. Interior, Mother and Sister of the Artist imaged using four different techniques: normal light, UVF, IRR, and XRR. Images rights: normal light ( 2021 Artists Rights Society (ARS), New York/ADAGP, Paris, all reproductions of this work are excluded from the CC: BY License; UVF, IRR, and XRR (C 2021 MoMA, N.Y.

Some pigment identification is also possible by way of imaging analysis. Autofluorescence in UVF can be helpful in mapping the prevalence of certain pigments across the composition [43]. The pink pigment in both faces, more heavily used in the cheeks, clearly autofluoresces as bright pink in UVF (Figure 5) and characteristic of a lake pigment, such as eosin [43]. In addition to the flesh tones, the autofluorescent pink pigment is found throughout the patterned background and in the small piece of food on the plate to the right of the mother and in the face of the sister. Bright orange autofluorescence in the plate and tablecloth also confirm the presence of a cadmium yellow [43], the white in both faces has a slightly greenish appearance in UVF, characteristic of zinc white (Figure 5), and as suggested by $\mathrm{p}$-XRF.

IRR confirmed the use of Prussian blue based on the absorption in the infra-red, characteristic of this pigment (Figure 5) [44]. This confirms the p-XRF analysis in conjunction with visual examination of the blue passages and MCR-ALS data exploration. IRR also visualized the use of a carbon-based black used overall in the mother's dress and in the dark colored baseboard, confirming $\mathrm{p}-\mathrm{XRF}$ identification of bone black.

\subsection{Artist Technique}

A sense of warm intimacy is a hallmark of Vuillard's small interior paintings. There is a harmonious color relationship throughout with complimentary tones of pinkish orange, 
greenish blue, ochres, maroons and black used throughout. Using almost cinematic devices such as close-cropping within the small room, Vuillard created atmosphere and tension within a perceived narrative. Not surprising, Vuillard is quoted as saying, "I don't do portraits, I paint people in their surroundings" [45]. He goes a step further in this painting by seemingly painting his sister into her environment. The busy wallpaper and patterning of the sister's dress along with her semi-bent posture also enhance the mystery of this depicted moment. The design of the wallpaper and of the sister's dress are applied using individual strokes and dabs of colors. Not only is the paint application method used for the sister like that of the patterned wallpaper, but the color palette for both is visually alike. Additionally, overall analysis confirms the presence of chrome orange, Prussian blue, chromium oxide green, and ochre in the sister's dress and on the wall behind her, seamlessly blending the palette to further place his sister within the room. Vuillard used both thick brushwork and thin washes of oil paint within this composition.

The use of MCR-ALS also elucidated the application of zinc and lead white pigments in the picture. Most intriguing is the distinction in the use of zinc white exclusively to blend with other colors in creating the haunting faces of his mother and sister, in addition to their hands. Zinc white is a popular choice as a base for flesh tones as it is a truer white and more transparent than lead. Vuillard's use of zinc white for flesh tones was also described in a previous study on his distemper techniques [3]. Lead white on the other hand was used more for the interior elements and clothing.

The technique used to paint the mother's face is visually different from the sister's face; the differences become clearer when comparing technical images. Microscopic examination (Figure 6) shows the artist reworked the mother's face by scraping or sanding far enough to expose the tops of the canvas nubs. The handling of the mother's face is especially interesting as the artist appears to have labored over this area in a way not seen in the sister's face. The paint is applied over an abraded surface as thin glazes and dilute scumbles. The nose and mouth are applied with an especially minimal approach relying on a few lines of black paint and dabs of pink and white. The brown canvas nubs and abraded ground remain clearly visible throughout the thin rendering of facial features (Figure 5). In contrast, the sister's face is painted much more directly with only minor reworking noticeable. Vuillard appears to have blocked in the eyes, nose and mouth before applying thick and confident opaque flesh-colored brushstrokes (Figure 5).

The sister's face is more unevenly radiopaque and modeled in the XRR and can be explained by the use of heavy lead chromates, possibly chrome orange, in concert with the zinc white and Geranium lake to create the fleshy pink tones and blushed cheek (Figure 7). While the UVF image shows bright fluorescence in the sister's cheek that can be indicative of eosin, it is not possible to confirm the extent of fading, if any, without a cross section [40]. The use of red lead could also contribute to the radiopacity observed in XRR but cannot be mapped with available techniques. Shadow play on the sister's face is accomplished with umber and bone black. However, the paint mixtures used to model their hands are quite distinct. The mother's hands are densely painted with a combination of cobalt blue, vermilion, and possibly chrome green, in addition to zinc white. In contrast, the sister's hands are softer and brighter due to the presence of eosin, in addition to chrome orange. Again, these tones are like the salmon-colored brush strokes that make up some of the patterning on the wall. 

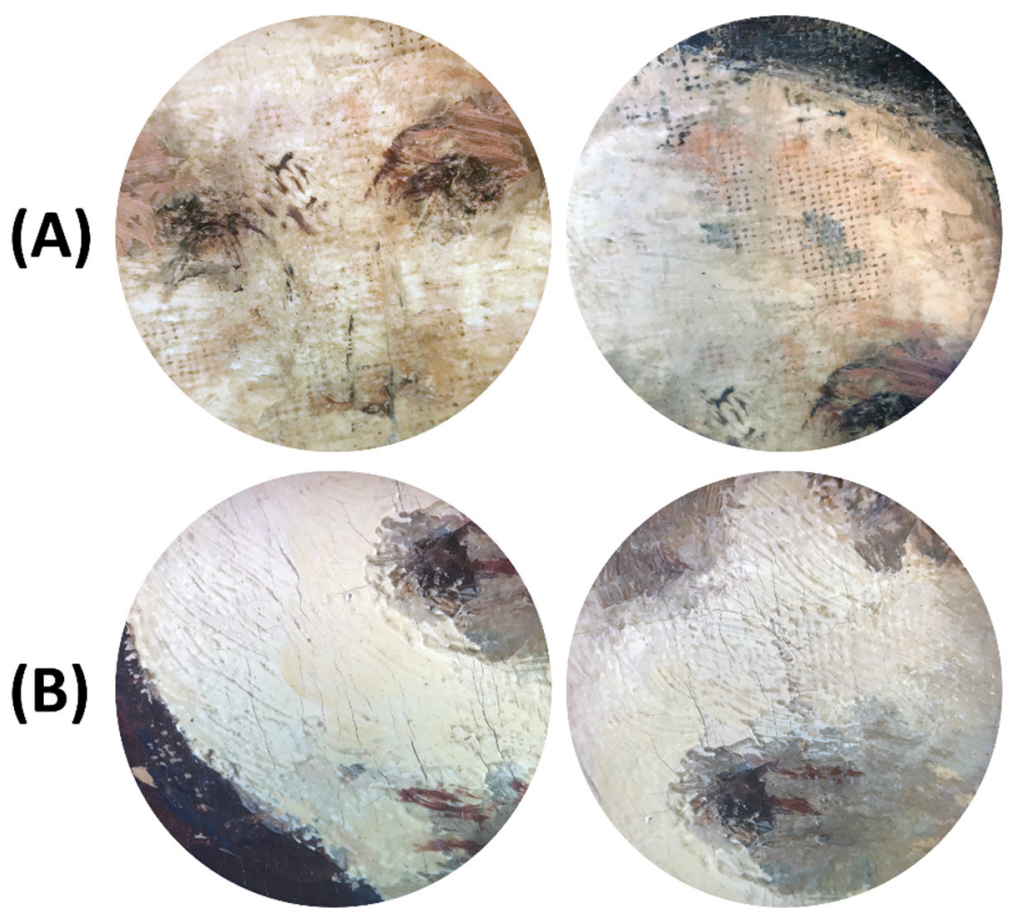

Figure 6. Details of the faces of the mother (A) and sister (B) depicted in Interior, Mother and Sister of the Artist that show Vuillard's treatment of the paint and canvas. (C) 2021 MoMA, N.Y.
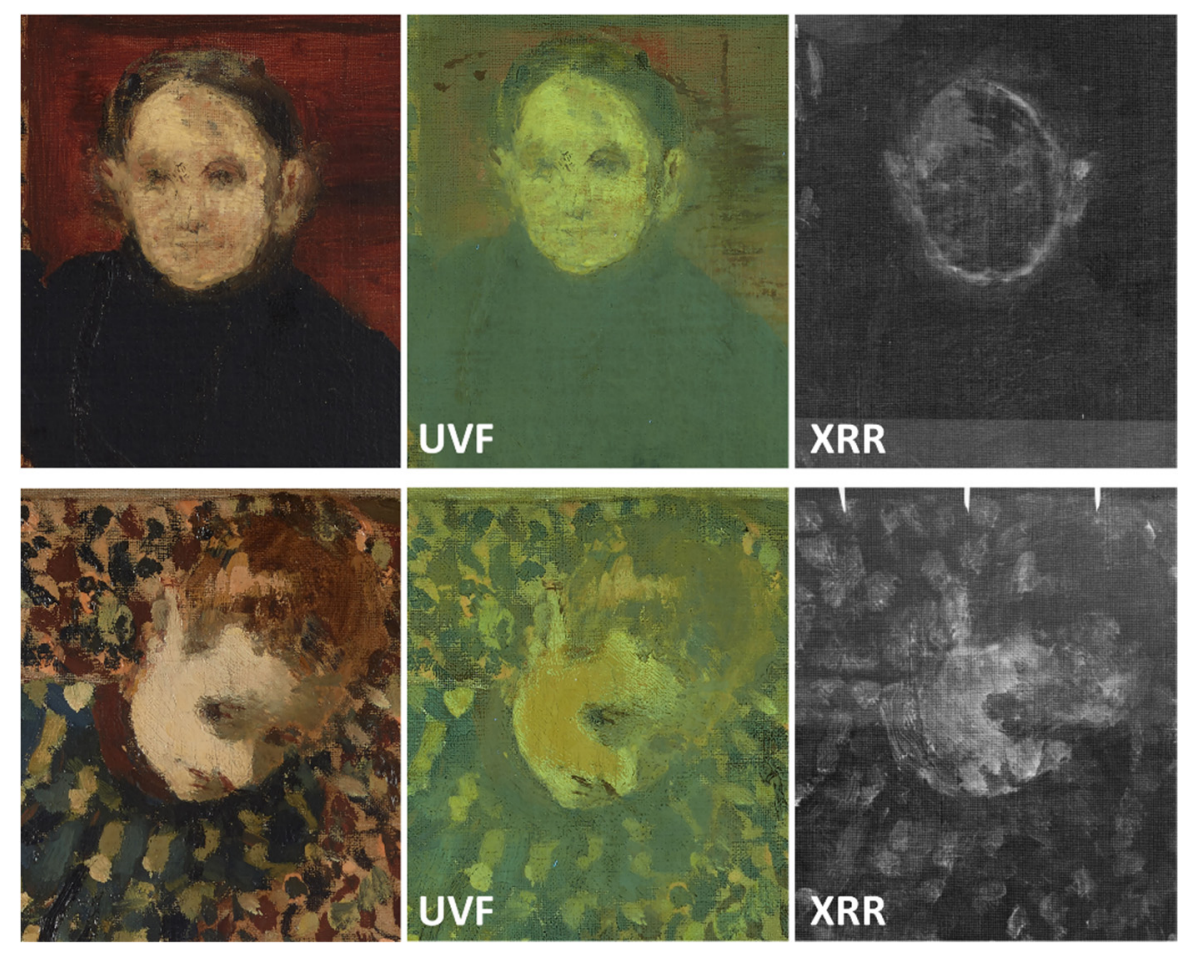

Figure 7. Details of Interior, Mother and Sister of the Artist imaged using three different techniques: normal light, UVF, and XRR. The top row details are of the mother's face and the bottom row are of the sister's face. Images rights: normal light (C 2021 Artists Rights Society (ARS), New York/ADAGP, Paris, all reproductions of this work are excluded from the CC: BY License; UVF, IRR, and XRR ( 2021 MoMA, N.Y. 


\section{Conclusions}

This technical study of Interior, Mother and Sister of the Artist (1893) shed light on the material choices and working methods used by Vuillard. The findings from the analytical investigation were supported by different imaging techniques to gain a better understanding of this striking painting. This collaboration highlights the interdisciplinary nature of this study, where conservation scientists worked in close concert with conservators. The unraveling of a lighter brown imprimatura layer is interesting considering the artist often worked on warmly toned substrates such as cardboard. Statistical analysis using a decomposition technique such as MCR-ALS complimented the individual spectral interpretation of $\mathrm{p}-\mathrm{XRF}$ data and helped pinpoint the distribution of some pigments across the picture. The pigments identified include lead white, zinc white, bone black, ochre, umber, vermilion, Geranium lake, red lead, ultramarine, Prussian blue, chrome yellow, chrome orange, zinc yellow, strontium yellow, cadmium yellow, and a chromium oxide green.

Author Contributions: A.H. carried out Raman Spectroscopy, SERS, $\mu$-FTIR, and XRF data acquisition and interpretation, statistical analysis, and drafting this manuscript. D.H. carried out sampling in addition to imaging and drafting the manuscript. A.M. supervised data interpretation and statistical analysis, and provided revisions of the manuscript. All authors have read and agreed to the published version of the manuscript.

Funding: This research received no external funding.

Data Availability Statement: Data are available upon request.

Acknowledgments: The authors are grateful for support from The David Booth Fellowship program in Painting Conservation (DH) and Conservation Science (AH). Authors are also grateful for support from Michael Duffy and Anny Aviram, painting conservators at the David Booth Conservation Department at the Museum of Modern Art.

Conflicts of Interest: The authors declare no conflict of interest.

Declaration: The opinions: findings, and conclusions or recommendations expressed in this publication are those of the authors and do not necessarily reflect those of the Museum of Modern Art. The au-thors declare no competing financial interest.

\section{References}

1. Ritchie, A.C. Édouard Vuillard; Museum of Modern Art: New York, NY, USA, 1954.

2. Kuenzli, K.M. The Nabis and Intimate Modernism: Painting and the Decorative at the Fin-de-Siècle; Routledge: Surrey, UK, 2016.

3. Robbins, A.; Stonor, K. Past, Present, Memories: Analysing Edouard Vuillard's "La Terrasse at Vasouy". Natl Gallery Tech Bull. JSTOR 2012, 33, 82-112.

4. Keck, S.; Keck, C. Vuillard, Mother and Sister of the Artist; Report No.: 543042; The Musuem of Modern Art: New York, NY, USA, 1954.

5. Stoner, J.H. Conservation of Easel Paintings, 1st ed.; Routledge: Surrey, UK, 2013.

6. Villers, C. (Ed.) Lining Paintings: Papers from the Greenwich Conference on Comparative Lining Techniques; Archetype: London, UK, 2003.

7. Groom, G.L., III; Watkins, N.; Paoletti, J.; Barruel, T. Beyond the Easel: Decorative Painting by Bonnard, Vuillard, Denis, and Roussel, 1890-1930; Yale University Press: New Haven, CT, USA, 2001.

8. Vuillard, T.M. Mother and Sister of the Artist; Treatment Report; Museum of Modern Art: New York, NY, USA, 1979.

9. Salomon, A.; Vuillard, E. Vuillard, the Inexhaustible Glance: Critical Catalogue of Paintings and Pastels; Skira: Milan, Italy, 2003.

10. Randolph, P.Y. History, analysis and treatment of "la salle a manger au chateau de clayes", 1938, by edouard vuillard. The Book and Paper Group Annual; ICCROM: Rome, Italy, 1984; Volume 3, pp. 112-121.

11. Daly, N.S.; Sullivan, M.; Lee, L.; Trentelman, K. Multivariate analysis of Raman spectra of carbonaceous black drawing media for the in situ identification of historic artist materials. J. Raman Spectrosc. 2018, 49, 1497-1506. [CrossRef]

12. Donais, M.K.; Wojtas, S.; Desmond, A.; Duncan, B.; George, D.B. Differentiation of Hypocaust and Floor Tiles at Coriglia, Castel Viscardo (Umbria, Italy) Using Principal Component Analysis (PCA) and Portable X-ray Fluorescence (XRF) Spectrometry. Appl. Spectrosc. 2012, 66, 1005-1012. [CrossRef]

13. Mitchell, G.; France, F.; Nordon, A.; Tang, P.L.; Gibson, L.T. Assessment of historical polymers using attenuated total reflectanceFourier transform infra-red spectroscopy with principal component analysis. Heritage Sci. 2013, 1, 28. [CrossRef]

14. Vandenabeele, P.; Hardy, A.; Edwards, H.G.M.; Moens, L. Evaluation of a Principal Components-Based Searching Algorithm for Raman Spectroscopic Identification of Organic Pigments in 20th Century Artwork. Appl. Spectrosc. 2001, 55, 525-533. [CrossRef] 
15. Romero-Pastor, J.; Cardell, C.; Yebra-Rodríguez, Á.; Rodríguez-Navarro, A.B. Validating chemical and structural changes in painting materials by principal component analysis of spectroscopic data using internal mineral standards. J. Cult. Heritage 2013, 14, 509-514. [CrossRef]

16. Hall, M.; Amraatuvshin, C.; Erdenbat, E. X-ray fluorescence analysis of pottery from Northern Mongolia. J. Radioanal. Nucl. Chem. 1999, 240, 763-773. [CrossRef]

17. Donais, M.K.; Duncan, B.; George, D.; Bizzarri, C. Comparisons of ancient mortars and hydraulic cements through in situ analyses by portable X-ray fluorescence spectrometry. X-ray Spectrom. 2010, 39, 146-153. [CrossRef]

18. Bro, R.; Smilde, A.K. Principal component analysis. Anal Methods 2014, 6, 2812-2831. [CrossRef]

19. de Juan, A.; Jaumot, J.; Tauler, R. Multivariate Curve Resolution (MCR). Solving the mixture analysis problem. Anal Methods 2014, 6, 4964-4976. [CrossRef]

20. Windig, W.; Shaver, J.; Keenan, M.R.; Wise, B.M. Simplification of alternating least squares solutions with contrast enhancement. Chemom. Intell. Lab. Syst. 2012, 117, 159-168. [CrossRef]

21. Martins, A.; Albertson, C.; McGlinchey, C.; Dik, J. Piet Mondrian's Broadway Boogie Woogie: Non invasive analysis using macro $\mathrm{X}$-ray fluorescence mapping (MA-XRF) and multivariate curve resolution-alternating least square (MCR-ALS). Heritage Sci. 2016, 4, 418. [CrossRef]

22. Martins, A.; Coddington, J.; Van Der Snickt, G.; Van Driel, B.; McGlinchey, C.; Dahlberg, D.; Janssens, K.; Dik, J. Jackson Pollock's Number 1A, 1948: A non-invasive study using macro-x-ray fluorescence mapping (MA-XRF) and multivariate curve resolution-alternating least squares (MCR-ALS) analysis. Heritage Sci. 2016, 4. [CrossRef]

23. Alfeld, M.; Janssens, K. Strategies for processing mega-pixel X-ray fluorescence hyperspectral data: A case study on a version of Caravaggio's painting Supper at Emmaus. J. Anal. At. Spectrom. 2015, 30, 777-789. [CrossRef]

24. Alfeld, M.; Wahabzada, M.; Bauckhage, C.; Kersting, K.; Wellenreuther, G.; Falkenberg, G. Non-negative factor analysis supporting the interpretation of elemental distribution images acquired by XRF. J. Physics: Conf. Ser. 2014, 499, 012013. [CrossRef]

25. Santos, H.; Caliri, C.; Pappalardo, L.; Catalano, R.; Orlando, A.; Rizzo, F.; Romano, F.P. Identification of forgeries in historical enamels by combining the non-destructive scanning XRF imaging and alpha-PIXE portable techniques. Microchem. J. 2016, 124, 241-246. [CrossRef]

26. Lux, C.; Lubio, A.; Ruediger, A.; Robert, S.; Muehlethaler, C. Optimizing the analysis of dyes by Surface-Enhanced Raman Spectroscopy (SERS) using a conventional-microwave silver nanoparticles synthesis. Forensic Chem. 2019, 16, 100186. [CrossRef]

27. Price, B.A.; Pretzel, B.; Lomax, S. (Eds.) Infrared and Raman Users Group Spectral Database, 2007 ed.; IRUG: Philadelphia, PA, USA, 2009; Volume 1-2.

28. Bell, I.M.; Clark, R.J.; Gibbs, P.J. Raman spectroscopic library of natural and synthetic pigments (pre- $\approx 1850$ AD). Spectrochim. Acta Part A Mol. Biomol. Spectrosc. 1997, 53, 2159-2179. [CrossRef]

29. Keenan, M.R.; Kotula, P. Optimal scaling of TOF-SIMS spectrum-images prior to multivariate statistical analysis. Appl. Surf. Sci. 2004, 231-232, 240-244. [CrossRef]

30. Derrick, M.R.; Stulik, D.; Landry, J.M. Infrared Spectroscopy in Conservation Science; Getty Conservation Institute: Los Angeles, CA, USA, 1999.

31. Helwig, K. Iron Oxide. In Artists Pigments Handb Their Hist Charact Vol 4; Berrie, B., Ed.; National Gallery of Art: Washington, DC, USA, 2007.

32. Hermans, J.J.; Keune, K.; Van Loon, A.; Iedema, P.D. An infrared spectroscopic study of the nature of zinc carboxylates in oil paintings. J. Anal. At. Spectrom. 2015, 30, 1600-1608. [CrossRef]

33. Hermans, J.J.; Keune, K.; Van Loon, A.; Stols-Witlox, M.J.; Corkery, R.W.; Iedema, P.D. The synthesis of new types of lead and zinc soaps: A source of information for the study of oil paint degradation. In Proceedings of the ICOM Comm Conserv 17th Trienn Conf Prepr Melb, Melbourne, Australia, 5-19 September 2014; pp. 15-19.

34. McGlinchey, C. Handheld XRF for the examination of paintings: Proper use and limitations. In Handheld XRF Art Archaeol; Shugar, A.N., Mass, J.L., Smith, D., Eds.; Leuven University Press: Leuven, Belgium, 2012.

35. Kuhn, H.; Chase, T.W. Lead white. In Artists Pigments Handb Their Hist Charact Vol 4; Gettens, R.J., Ed.; National Gallery of Art: Washington, DC, USA, 1993.

36. Kirby, K.; Saunders, D. Fading and Colour Change of Prussian Blue: Methods and Manufacture and the Influence of Extenders. Natl Gallery Tech Bull. 2004, 25, 73-99.

37. Kuhn, H.; Curran, M. Chrome Yellow and Other Chromate Pigments. In Artists Pigments Handb Their Hist Charact Vol 1; Feller, R.L., Ed.; Cambridge University Press: New York, NY, USA, 1987.

38. Cesaratto, A.; Leona, M.; Pozzi, F. Recent Advances on the Analysis of Polychrome Works of Art: SERS of Synthetic Colorants and Their Mixtures With Natural Dyes. Front. Chem. 2019, 7, 105. [CrossRef]

39. Centeno, S.A.; Hale, C.; Carò, F.; Cesaratto, A.; Shibayama, N.; Delaney, J.; Dooley, K.; Van Der Snickt, G.; Janssens, K.; Stein, S.A. Van Gogh's Irises and Roses: The contribution of chemical analyses and imaging to the assessment of color changes in the red lake pigments. Heritage Sci. 2017, 5, 18. [CrossRef]

40. Sabatini, F.; Eis, E.; Degano, I.; Thoury, M.; Bonaduce, I.; Lluveras-Tenorio, A. The issue of eosin fading: A combined spectroscopic and mass spectrometric approach applied to historical lakes. Dye. Pigment. 2020, 180, 108436. [CrossRef]

41. Chieli, A.; Miliani, C.; Degano, I.; Sabatini, F.; Tognotti, P.; Romani, A. New insights into the fading mechanism of Geranium lake in painting matrix. Dye Pigment. 2020, 181, 108600. [CrossRef] 
42. Thoury, M.; Elias, M.; Frigerio, J.M.; Barthou, C. Nondestructive Varnish Identification by Ultraviolet Fluorescence Spectroscopy. Appl. Spectrosc. 2007, 61, 1275-1282. [CrossRef]

43. Stuart, B. Analytical Techniques in Materials Conservation; John Wiley \& Sons: Chichester, UK; Hoboken, NJ, USA, 2007.

44. Favero, P.A.; Mass, J.; Delaney, J.K.; Woll, A.R.; Hull, A.M.; Dooley, K.A.; Finnefrock, A.C. Reflectance imaging spectroscopy and synchrotron radiation $X$-ray fluorescence mapping used in a technical study of The Blue Room by Pablo Picasso. Heritage Sci. 2017, 5, 26. [CrossRef]

45. Cogeval, G.; Vuillard, E.; Jones, K.; Des Cars, L.; Gamboni, D.; Stevens, M.A. Édouard Vuillard; Yale University Press: New Haven, CT, USA, 2003. 